\title{
Hastane Öncesi Alanda Ventriküler Fibrilasyonu Olan Hastada Erken Defibrilasyon: Olgu Sunumu
}

\author{
Early Defibrillation In A Patient With Ventricular Fibrillatıon In The Pre- \\ Hospital Area: Case
}

\author{
Batuhan TAY ${ }^{1}$, Emine SEVINCÇ ${ }^{2}$ \\ ${ }^{1}$ Balıkesir İl Sağlık Müdürlüğü Burhaniye 1 Nolu 112 Acil Sağlık Hizmetleri İstasyonu. Balıkesir \\ taybatuhan@hotmail.com ORCID ID: 0000-0003-0178-628X (Sorumlu Yazar)
}

${ }^{2}$ Dr. Öğr. Üyesi Çanakkale Onsekiz Mart Üniversite Sağlık Hizmetleri MYO, İlk Ve Acil Yardım Programı. Çanakkale emnsvnc@gmail.com ORCID ID: 0000-0002-2816-4029

Geliş tarihi/Received: 19.03.2021

Kabul tarihi/Accepted: 16.04.2021

Yayın tarihi/Online published:15.12.2021

\section{ÖZET}

Paramediklerin, ölümcül aritmisi olan hastalarda erken ön tanıya gitmeleri ve etkin ileri yaşam desteğini sağlamaları hayati öneme sahiptir. Olgu 112'ye göğüs ağrıs ve terleme şikayeti ile başvurmuştur. Makalede hastane öncesi alanda ventriküler fibrilasyon yönetimi ve erken defibrilasyonun öneminin vurgulanması amaçlandı. Hastaya ulaşı1dığında cilt rengi soluk ve terli, eliyle ise göğüs bölgesini tuttuğu gözlemlenmiş̧tir. Hasta, elektrokardiyografi çekebilmek için sedyeye alındığı sırada hastanın bilinci kapanmış ve nabız alınamamıştır. Kardiyo pulmoner resüsitasyon'a başlanılmış, kardiyak ritmi kontrol edildiğinde hastanın ventriküler fibrilasyonda olduğu anlaşılmıştır. Defibrilatör cihazı 200 joule ayarlanarak defibrilasyon uygulanmıştır. Defibrilasyondan sonra glaskow koma skoru 15 olacak şekilde spontan dolaşımın geri dönüşü sağlanılmıştır.

Anahtar Kelimeler: Erken defibrilasyon, kardiyak arrest, ventriküler fibrilasyon.

\begin{abstract}
It is vital that paramedics undergo early diagnosis and provide effective advanced life support in patients with fatal arrhythmias. Case 112 applied to 112 with complaints of chest pain and sweating. The aim of the article was to emphasize the importance of ventricular fibrillation management and early defibrillation in the prehospital area. When the patient was reached, it was observed that his skin was pale and sweaty, and he held the chest area with his hand. When the patient was taken to the stretcher to have an electrocardiogram, the patient became unconscious and the pulse could not be taken. Cardio pulmonary resuscitation was initiated, and when the cardiac rhythm was controlled, it was understood that the patient was in ventricular fibrillation. Defibrillation was applied by adjusting the defibrillator device to 200 joules. After defibrillation, the return of spontaneous circulation was achieved with a glaskow coma score of 15 .
\end{abstract}

Keywords: Early defibrillation, cardiac arrest, ventricular fibrillation. 


\section{Gİiș}

Dünya çapında hastane dışı kardiyak arrest (KA) insidansı iyi tanımlanmamıştır. ABD'de her y1l yetişkinlerde 290.000 'den fazla hastane içi kardiyak arrest görülürken, yetişkinler arasında 326.000 hastane dişı KA vakası meydana gelmektedir (SHARABI \& SINGH, 2020). Hastane dışı KA'ların büyük bir çoğunluğunda ilk kaydedilen ritim ventriküler fibrilasyondur (VF). VF gibi şoklanabilir bir ritme sahip olan hastalarda defibrilasyondaki her bir dakika geç kalmanın sağ kalımı \%5-10 oranında azalttığı düşünülmektedir. $\mathrm{Bu}$ nedenle hastalarda erken resüsitasyon ve erken defibrilasyon hayat kurtarmaktadır (DURUSU TANRIÖVER, 2011). VF ve nabızsız ventriküler taşikardi gibi şok verilebilir ritimler, anında defibrilasyon gerektirir ve şoklanabilir ritmi olan hastalarının genellikle şok verilemez ritmi olanlara göre daha yüksek sağ kalımlara ve iyi nörolojik sonuçlara sahip oldukları kabul edilir (Majewski, Ball, Bailey, Bray, \& Finn, 2021)

Olgu 112'ye göğüs ağrısı ve terleme şikayeti ile başvurmuş 59 yaşında erkek hastadır. Çalışmada hastane öncesi acil sağlık hizmetleri personelinin VF yönetimi ve erken defibrilasyonun önemini vurgulamayı amaçlandı. Hastadan olgu sunumunun yapılabilmesi için yazılı ve sözlü olarak izin alınmış olup, bilgilendirilmiş onam formu imzalatılmıştır.

\section{OLGU}

Hastane öncesi acil sağllk ekibi saat 06:20 sularında, evinde göğüs ağrısı ve terleme şikayeti olan 59 yaşındaki erkek hasta için görevlendirilmiştir. Bir paramedik, bir acil tıp teknisyeni ve bir sürücüden oluşan ekip hazırlıklarını yaparak çıkış yapmış ve yaklaşık 7 dakika sonra adrese ulaşmıştır. Ekip, göğüs ağrısı şiddetlendiğinden dolayı ambulansı beklemek yerine arabasıyla hastaneye gitmeye karar veren hasta ile arabasına binmek üzereyken sokakta karşılaşmıştır. Hastanın cilt rengi soluk ve terli, eliyle ise göğ̈̈s bölgesini tuttuğu gözlemlenmiştir.

Daha sonra hastayı ambulansa alındı. Yaşam bulgularını almak ve elektriyokardiyografi (EKG) çekebilmek için sedyeye oturtulduğu sırada hastanın bilinci kapandı. Karotis arterden nabız palpe edildiğinde, nabız alınamamış ve KA olduğu anlaşıllmıştır.

KA olan hasta sedyeye yatırılmış, kardiyopulmoner resüsüsitasyon(KPR) için uygun bir zemin hazırlandıktan sonra, hemen KPR'a başlanılmış ve ileri yaşam desteği algoritması devreye sokulmuştur. Hastaya KPR yapılırken hastanın kardiyak ritmi takip etmek için, vakit kayb1 yaşamak istenmediğinden, defibrilatör kaşıkları aracılığıyla hastanın ritmi kontrol edilmiştir. Kardiyak ritmin VF olarak belirlenmesi üzerine, hastaya paramedik tarafindan defibrilasyon uygulanmaya karar verilmiştir. Bifazik defibrilatör ile 200 joule ayarlanarak hastaya defibrilasyon uygulanmıştır.

İlk defibrilasyon sonrası hastaya 2 dakika boyunca KPR yapılmaya devam edilmiştir. Hastaya defibrilatör elektrotları da bağlanılarak monitörize edilmiştir. 2 dakikalık KPR sonucunda tekrar ritim kontrolü yapıldığında ise hastanın tekrar VF ritminde olduğu tespit edilmiştir. Hemen ikinci defibrilasyon hazırlıkları başlanmış ve tekrar 200 joule ile hasta defibrile edilmiştir. İkinci defibrilasyon sonrasında hastaya ritim kontrolünden önce 2 dakikalık KPR yapılacağı sirada hasta bilinci açılmış, Glaskow Koma Skalası skoru 15'e 
yükselmiş ve göğüs basısı yapılmasına izin vermemiştir. Hastanın ritim kontrolü yapıldığında sinüs ritminde olduğu tespit edilmiştir. Hastaya yaklaşık 4 dakika boyunca KPR uygulandıktan sonra spontan dolaşımının geri dönüşü (SDGD) gerçekleşmiştir. Aynı zamanda hastaya 4-5 dakika boyunca balon walf maske(ambu) aracılığı ile $\% 100$ oksijen ile verilmiştir ve ileri hava yolu teknikleri uygulanana kadar hastanın spontan solunumu geri gelmiştir. $\mathrm{Bu}$ KPR sonrasında hastanın intravenöz (IV) yolu sağlanmış ve kardiyojenik şoka karşı $500 \mathrm{ml}$ \%0,9 Sodyum Klorür ile sıvı replasmanı başlanılmıştır. Hastanın damar yolu açıklığı SDGD'den sonra sağlanabildiğinden dolayı \%0,9 Sodyum Klorür dışında herhangi bir ilaç uygulaması yapılmamıştır. Daha sonra yaşam bulguları alınmış kan basıncı 100/60 mmhg, nabız 80/dk saturasyon değeri \%98 olarak ölçülmüştür.
Hastanın hastaneye nakli sağlanırken 2. bir damar yolu açılmış, kendisinden anamnez alınmaya çalışılmıştır. Hasta kendisinin herhangi bir kronik rahatsızlığının olmadığını ve göğüs ağrısının 2 veya 3 gündür hafif olduğu, olay sabahı ağrının iyice şiddetlendiği dayanılmaz bir hal aldığını ifade etmiştir.

Hastanın spontan dolaşımı sağlanıldıktan sonra 4 dakika içerisinde anjiografi ünitesinin olmadığ fakat ilçedeki tek hastane olduğu için ilçe hastanesine nakledilmiş ve kırmızı kod ile acil servise giriş yapılmıştır. Daha sonra hastanenin acil servisinden ileri tetkik ve tedavi amaçlı olarak, hasta anjiyografi ünitesi mevcut olan bir hastaneye sevk edilmiştir. Hastanın 6 ay sonunda sağlık durumu gayet iyi, herhangi bir nörolojik sekeli olmadan ve sağlıklı bir şekilde yaşamını sürdürmektedir.

\section{TARTIŞMA}

Ventriküler miyokardiyumdan veya his-purkinje sisteminden kaynaklanan aritmiler ventriküler aritmi altında gruplanır. $\mathrm{Bu}$, ventriküler taşikardi, ventriküler fibrilasyon, erken ventriküler kasılmalar ve ventriküler flutter gibi bir aritmi alt kümesini içerir. VF, düzensiz elektriksel aktivitenin neden olduğu bir geniş kompleks taşikardidir ve EKG'de ayrı QRS kompleksleri ile genellikle 300'den büyük bir ventriküler hız ile karakterize edilir. VF, kalp debisini önemli ölçüde tehlikeye atan ve sonucunda kardiyak arreste yol açan son derece tehlikeli bir ritimdir. EKG bulgularında; trasede değişken genişlik ve şekle sahip fibrilasyon dalgaları, tanımlanabilir P dalgaları, QRS kompleksleri veya $\mathrm{T}$ dalgaları yoktur, kalp atım hızı 150-500 arasındadır (LUDWHANI, GOYAL, \& JAGTAP, 2020).

KA sonrasında sağ kalım, büyük ölçüde resüsitatif bakımın kalitesine bağlıdır. KA'nın erken dönemde tanınması, KPR'1n erken başlatılması, erken defibrilasyon ve yüksek kaliteli göğüs basıları gibi birçok temel belirleyici, hasta sonuçlarını etkileyecek önemli değişkenlerdir (CHENG, ve diğerleri, 2020).

Amerikan Kalp Derneği (AHA) tarafından 2020 yılında güncellenen ileri yaşam desteğine göre hastanın dolaşımı değerlendirilir ve eğer dolaşımı yok ise hastaya hemen KPR'ye başlanır. Hasta monitörize edilir ve ritim değerlendirilir eğer şoklanamaz bir ritim (asistoli veya nabızsız elektriksel aktivite gibi) mevcut ise KPR'ye devam edilir. IV veya intraosseoz (IO) yol en erken zamanda sağlanmalı ve 3-5 dakikada bir gerekli dozlarda adrenalin uygulanmalıdır. 2 dakikalık bir KPR sonunda ritim tekrar değerlendirilir ve şoklanamaz bir ritim var ise aynı döngü devam eder. Hastanın geri döndürülebilir nedenleri tespit 
edilip tedavi edilmeye çalışılır (PANCHAL, ve diğerleri, 2020).

Eğer hastada şoklanabilir bir ritim var ise; uygun joulede şok uygulanır ve hemen arkasından KPR 2 dakika boyunca devam etmelidir. 2 dakikanın sonunda ritim tekrar değerlendirilmelidir. Tekrar şoklanabilir ritim var ise aynı döngü tekrarlanır fakat ikinci defibrilasyondan sonra 3-5 dakikada bir uygun dozda adrenalin uygulanmaya başlanması ve üçüncü defibrilasyondan sonra ise uygun dozda amiodaron veya lidokain başlanması gerekmektedir (PANCHAL, ve diğerleri, 2020).

2005 yılında yapılan bir çalışmada otomatik eksternal defibrilatör kayıtları incelendiğinde, hastaların \%21,1'inde olay yerinde SDGD sağlanmıştır. Aynı çalışmada hastalara ilk şok verilme süresi yaklaşık 8 dakika ve ortalama şok sayısı ise 1,9 olarak tespit edilmiştir. Hastaların \%21'inin hastaneden taburcu olduğu tespit edilmiştir (KO, CHEN, LIN, MA, \& LIN, 2005). 2008 yılında yapılan bir çalışmada ise hastaların \%53,3'ü, ortalama 3,61 defibrilasyon ile SDGD sağlanmıştır. Ambulansların olay yerine varış süresi ise 8 dakika 14 saniye olduğu ve hastaların \%17,1'i hastaneden sağ bir şekilde taburcu olduğu belirtilmiştir (BAKER, ve diğerleri, 2008). Nichol ve arkadaşlarının 2008 yılında yaptığg bölgesel bir çalışmada 20520 hastane dışı KA vakası incelenmiştir. İncelenen bu vakaların \%22,9'unda şoklanabilir bir ritim tespit edilmiş ve bu vakaları \%4,6's1 hastaneden sağ olarak taburcu edilmiştir. Hastane öncesi acil sağlık ekiplerinin olay yerine geliş süreleri ortalama 7 dakika 24 saniyedir (NICHOL, ve diğerleri, 2008). Bizim olgumuzda ise hastanın ikinci şokunda SDGD sağlanılmış ve hastaya ulaşım süresi 7 dakika olarak belirlenmiş ve hasta şifa ile hastaneden taburcu edilmiştir.

2010 y1lında yayınlanan bir olgu sunumunda ise 49 yaşındaki bir erkek hastaya 26 dakika boyunca hasta yakını tarafindan, daha sonrasında ise olay yerine gelen hastane öncesi acil yardım ekibi tarafindan 49 dakika boyunca ileri yaşam desteği uygulandığı ve dördüncü defibrilasyondan sonra hastanın SDGD sağlandığı görülmektedir. Hasta 8 gün hastanede kaldıktan sonra herhangi bir nörolojik hasarı olmadan taburcu edilmiştir (STEEN-HANSEN, 2010).

2016 yılında yayınlanan bir olguda ise 28 yaşındaki bir kadın hasta hastane dışında KA olmuştur. Hasta KA olduktan sonra ilk defibrilasyon işlemi 10 dakika sonra uygulanmış ve 25,5 dakika sonra hastanın SDGD sağlanmıştır. Hasta 18 gün sonra orta derecede serebral yetersizlik ile hastaneden taburcu edilmiştir (JOHNSTON, CHESKES, ROSS, \& VERBEEK, 2016).

\section{TEŞEKKÜR}

$\mathrm{Bu}$ vakada benim ile görevlendirilen arkadaşlarım Neslihan BIYIKLI ve Şenol ŞENYÜZ, hastanın sağlığı için en az benim kadar çaba harcadıklarından dolayı bu büyük emeklerine teşekkürü bir borç bilirim.

\section{SONUÇ}

Paramedikler tarafından iyi organize edilmiş ileri yaşam desteği ve erken defibrilasyon, hastane dışında KA olan hastalar için sağlıklı bir şekilde SDGD için birinci kuraldır. $\mathrm{Bu}$ sebeple paramedikler, hastane öncesi alanda kardiyak arrest ve kardiyak arreste en çok sebep olan ritimlerden biri olan VF konusunda sürekli bir eğitime tabi tutulmalıdir. 


\section{KAYNAKLAR}

Baker, P. W., Conway, J., Cotton, C., Ashby, D. T., Smyth, J., Woodman, R. J., \& Grantham, H. (2008, 12). Defibrillation Or Cardiopulmonary Resuscitation First For Patients With Out-OfHospital Cardiac Arrests Found By Paramedics To Be İn Ventricular Fibrillation? A Randomised Control Trial. Resuscitation, 79(3), 424-431.

Cheng, A., Magıd, D. J., Auerbach, M., Bhanj1, F., Bigham, B. L., Blewer, A. L., . . . Donoghue, A. (2020, 10 21). Part 6: Resuscitation Education Science: 2020 American Heart Association Guidelines For Cardiopulmonary Resuscitation And Emergency Cardiovascular Care. Circulation, 142(16), 551-579.

Durusu Tanrı̈̈ver, M. (2011). Kardiyak Arrest Öncesinde Kötüleşen Hastayı Tanımak: Öngörü Kriterleri Ve Risk Faktörleri. Yoğun Bakım Dergisi, $1,16-20$.

Johnston, M., Cheskes, S., Ross, G., \& Verbeek, R. P. (2016). Double Sequential External Defibrillation And Survival From Out-Of-Hospital Cardiac Arrest: A Case Report. Prehospital Emergency Care Journal, 20(5), 662-666.

Ko, P. C.-I., Chen, W.-J., Lin, C.-H., Ma, M. H.-M., \& Lin, F.-Y. (2005). Evaluating The Quality Of Prehospital Cardiopulmonary Resuscitation By Reviewing Automated External Defibrillator
Records And Survival For Out-Of-Hospital

Witnessed Arrests. Resuscitation, 64(2), 163-169.

Ludwhanı, D., Goyal, A., \& Jagtap, M.

(2020). Ventricular Fibrillation.

Majewski, D., Ball, S., Bailey, P., Bray, J., \& Finn, J. (2021). Long-Term Survival Among Ohca Patients Who Survive To 30 Days: Does İnitial Arrest Rhythm Remain A Prognostic Determinant? Resuscitation, 162, 128-134.

Nichol, G., Thomas, E., Callaway, C. W., Hedges, J., Powell, J. L., Aufderhe1de, T. P., . . . Stiell, I. (2008). Regional Variation İn Out-OfHospital Cardiac Arrest Incidence And Outcome. Jama, 300(12), 1423-1431.

Panchal, A., Bartos, J. A., Cabanas, J. G., Donnıno, M. W., Drennan, I. R., Hirsch, K. G., . . . Chair, V. (2020). Part 3: Adult Basic And Advanced Life Support: 2020 American Heart Association Guidelines For Cardiopulmonary Resuscitation And Emergency Cardiovascular Care. Cieculation, 142(16), 366-468.

Sharab1, A. F., \& Singh, A. (2020).

Cardiopulmonary Arrest In Adults.

Steen-Hansen, J. E. (2010). Favourable Outcome After 26 Minutes Of "Compression Only" Resuscitation: A Case Report. Scandinavian Journal of Trauma, Resuscitation And Emergency Medicine, 18(19). 